\title{
Del reformador activo (Cisneros) al reformador contemplativo (Vitoria)
}

\section{From the active reformer (Cisneros) to the contemplative reformer (Vitoria)}

La apuesta por la reforma de la Iglesia, de sus jerarquías y órdenes es una tarea que en la península Ibérica va ganando adeptos desde el siglo XV, y a la que se entregan con entusiasmo tanto los Reyes Católicos como muchos religiosos. Dentro de estos, el cardenal Cisneros y Francisco de Vitoria representan dos formas de vivir y apoyar esa reforma y de difundir sus valores: más práctica, centrada en el ámbito hispano y apoyada en recursos políticos la del franciscano, y más teórica, universalista y fundada en principios morales la del dominico.

\section{\#Cisneros \#Francisco de Vitoria \#reforma religiosa \#vida activa \#contemplación}

The commitment to the reform of the Church, its hierarchies and orders is a task that is gaining adherents since the fifteenth century in the lberian Peninsula, and in which both the Catholic Monarchs and many religious are enthusiastically engaging. Among these, the Cardinal Cisneros and Francisco de Vitoria represent two ways of living and supporting this reform and of spreading its values: the Franciscan is more practical, centered in the Hispanic sphere and supported by political resources, while the Dominican appears more theoretical, universal and founded in moral principles. 


\section{Cisneros: un contemplativo que destaca en la vita activa}

La existencia desde el siglo XV de varias corrientes de espiritualidad peninsulares que ponían sus anhelos generales en la reforma del cristianismo para devolverle su pureza originaria, es un hecho hace tiempo constatado. Dentro de esos movimientos de inspiración diversa y variado desarrollo van a ocupar un lugar fundamental las órdenes franciscana (Andrés, 1976 y 1988; Rucquoi, 1996) y dominica (Beltrán de Heredia, 1939 y 1972), donde transcurren las vidas de Francisco Jiménez de Cisneros y Francisco de Vitoria.

El primero de ellos, aunque poseía su título de Bachiller en Decretos y le acompañó toda su vida la fama de devoto, no fue un hombre de letras ni un predicador en busca de su idea de Dios, sino un fraile que acabó desempeñando responsabilidades religiosas y políticas de enorme importancia. Es este oficio (Caro, 1970; Castilla, 2002, pp. 187-195), la manera de abordar esas dos facetas atendiendo a las circunstancias y a las expectativas que genera el ejercicio del correspondiente cargo, que en su caso fueron muchos y algunos de ellos de los más relevantes que existían en la Iglesia y en los reinos hispanos, lo que distingue y caracteriza al cardenal Cisneros. Considerarlo contemplativo es solo una manera de situarlo en el movimiento de reforma y espiritualidad que abraza desde el momento que ingresa en 1484, cuando le faltan dos años para cumplir el medio siglo, en la Orden franciscana, pero no quiere decir que sea ajeno a una actividad que en su caso fue múltiple y que va a ser tanto más importante a partir precisamente de ese momento. Como ha señalado Joseph Pérez (2014, p. 341): "Ser contemplativo no implica que uno se quede apartado de toda actividad: en el siglo $\mathrm{XVI}$, Teresa de Jesús es prueba de lo contrario: llevó una intensa actividad como fundadora de conventos sin dejar por eso de ser una contemplativa. Cisneros sería otro ejemplo".

Desde la perspectiva de esos oficios o cargos a los que se entregó el Cardenal, podemos hablar de él como un practicante de esa vida activa que ensalzaron algunos humanistas de la época, primero en Italia (Baron, 1993) y después en el resto de Europa, incluida la península Ibérica (Castilla, 2013, pp. 29-68; Valero, 2015). A esta forma de vida se asociaban valores como la riqueza, el valor militar, el patriotismo, el reconocimiento del mérito individual, la búsqueda de honores y fama o la vida familiar, que Cisneros no llegó a reivindicar en ningún momento, pero que no fueron en absoluto ajenos a su vida.

Para no extenderme en exceso, apoyaré mi tesis en dos momentos significativos de la biografía de Cisneros: primero, su nombramiento como arcipreste de Uceda, porque constituye el primer cargo distinguido de su carrera, si es que no ejerció de corregidor en la misma zona con anterioridad (Vázquez, 2016); en segundo lugar, su paso por el convento de La Salceda, que pudiera parecer un ejemplo contrario a esa vida activa a la que aludo.

El acceso de Cisneros al arciprestazgo de Uceda, que desempeñaba Pedro García de Guaza, estuvo basado en una maniobra poco digna: Cisneros acusó al arcipreste ante la curia 
papal de haber violado el fuero eclesiástico al entregar a la justicia civil a Pedro Encina, acusado de robo, pero que, amparándose en que había sido tonsurado antes de casarse y refugiándose en la iglesia de Torrelaguna, pretendía escapar al castigo. El arcipreste lo entregó a la justicia, que no dudó en ejecutar la sentencia de muerte. La denuncia provocó su destitución y a la vez el nombramiento de Cisneros en virtud de la bula Litterarum scientia, que se había fechado en Roma el 22 de enero de 1471 (García Oro, 1992, I, p. 30). El futuro cardenal debió aprovechar su estancia en la ciudad de los papas, que de ser válida la cronología propuesta por Vázquez (2016) quedaría reducida a su mínima expresión, para atraerse el apoyo de personas influyentes. Incluso llegó a obtener una bula de expectativa, una práctica no por extendida menos ilegítima, pues había sido prohibida por el Concilio de Letrán en el siglo XII (Rummel, 1999, p. 13), que le autorizaba a tomar posesión del primer beneficio eclesiástico que vacase en la diócesis de Toledo.

Dicho sea de paso, el asunto de los que se retraían por delitos a las iglesias, tan importante en la época, aparece en las lecciones de Vitoria (Heredia, 1931, p. 39), como aparece también en sus relecciones el de la exención de los eclesiásticos ante los tribunales civiles. Al final de la primera relección Sobre el poder de la Iglesia se menciona que: "Los gobernadores y todos los magistrados por debajo del príncipe yerran y pecan gravemente llevando a los tribunales a los eclesiásticos, por perniciosos que sean, contra sus privilegios, como también extrayendo de la Iglesia a los criminales, fuera de los casos permitidos en el derecho" (I, p. 603). Esto último, los que son detenidos en los lugares sagrados sin que medie autorización expresa de la autoridad facultada para ello, es también el objeto de un parecer de Vitoria de fecha desconocida, en el que su respuesta viene precedida por una similar de Domingo de Soto, y que mantiene que los jueces seculares se exceden en sus actuaciones si no les avala el Derecho ni lo manda el rey o sus consejeros, incurriendo con ello en la consiguiente pena:

Yo no sé responder determinadamente al caso, porque veo que cada día lo hacen los jueces seculares. Digo que a ellos me remito, pues son buenos letrados; que, si el Derecho se lo concede en el tal caso, o se lo manda el rey o los de su Consejo en sus provisiones, que muy bien lo pueden hacer. Pero si el Derecho no se lo concede, ni se lo manda el rey ni los de su Consejo en sus provisiones, no hallo por donde excusar a los tales jueces seculares de pecado y de excomunión y restitución. (De los que se retraen por delitos a las Iglesias, 1931, p. 175).

Volviendo a Cisneros, sus biógrafos coinciden en relacionar el episodio de Torrelaguna con sus apetitos más terrenales. Así, García Oro (1992, I, p. 30): "Este paso del bachiller evidenciaba que tenía ambiciones de alcanzar los mejores puestos en la escala beneficial y sobre todo que sabía ingeniarse para conquistarlos"; Joseph Pérez (2014, p. 28) no es menos contundente: "Esto fue lo que le sirvió de pretexto al futuro cardenal Cisneros para satisfacer sus ambiciones personales". Tales ambiciones insertan claramente a Cisneros en la vita 
activa, y se corresponden con su trayectoria inmediata, abandonando al arzobispo Alonso de Carrillo, que llegó a encarcelarlo por negarse a renunciar como arcipreste de Uceda, y poniéndose bajo la protección del cardenal Pedro González de Mendoza, que reconocería su valía nombrándolo Capellán Mayor de la iglesia de Sigüenza y Vicario General del obispado. Esta trayectoria triunfante le convierte en un letrado rico en los primeros años de la década de 1480. Sin embargo, cuando acumula beneficios y su fama se extiende más allá del mundo eclesiástico, hasta ser designado administrador temporal de Juan de Silva, conde de Cifuentes, mientras participa en las campañas granadinas (García Oro, 1992, I, pp. 39-40), abandona su privilegiada posición y se transforma en fraile franciscano de la observancia más exigente. Ingresa en el convento de La Salceda e incluso cambia de nombre, de Gonzalo a Francisco, en honor al fundador de la Orden, lo que parece expresar la aspiración a alejarse de los éxitos terrenales. Pero, aunque fuera su deseo de dedicarse a la vida contemplativa lo que propició esta conversión, nunca será un auténtico ermitaño alejado del mundo, no solo porque en cuanto fue posible tras su ingreso fue nombrado por sus compañeros guardián o superior de la comunidad, anticipando otros cargos importantes a los que estaba destinado, sino porque su reconocida valía lo hacía imposible:
La fervorosa reclusión de Fray Francisco en La Salceda no supuso su ocultamiento respecto a sus admiradores. No lo pretendió tampoco. Acaso su gusto se decantaba más bien por un eremitismo itinerante, en compañía de algunos frailes de su estilo. Con este acomodo sería posible atender a las muchas demandas de sus amigos, sin dejar de seguir su vida de retiro. (García Oro, 1992, I, p. 44).

Esto es, que el contemplativo Cisneros sigue inmerso en la vida activa durante este tiempo. Por otra parte, su entrega a la observancia franciscana coincide con las simpatías que la reina Isabel, siguiendo las tendencias de sus predecesores en el trono castellano (Nieto, 1990), mantiene hacia esta corriente espiritual tan radical (Meseguer, 1959), por lo que, sin duda, como se ha dicho, su retiro "le sirvió más de trampolín político que de separación total con el mundo" (Martínez, 2011, p. 86). Su posterior elección como confesor real le obliga a convertirse en un cortesano, aunque no deja de prevenir su conciencia solicitando que se le permita ser acompañado de otros hermanos de hábito, que pueda permanecer en lugares "desiertos y solitarios" para "hacer penitencia", confesarse con cualquier sacerdote si no encuentra alguno de su Orden, administrar la Penitencia y la Eucaristía sin solicitar licencia a los ordinarios y -siempre que sea posible- acceder a cualquier eremitorio franciscano cercano sin permiso de sus superiores (Torre, 1940, p. 47).

Los Reyes Católicos, que favorecieron de manera generalizada la rectitud de los obispos y el cumplimiento de las obligaciones del clero (García Oro, 1969; Azcona, 2015; Barrio, 2014), no dejarán de comprometerle con las tareas que estaban destinadas a darle fama. Como colaborador de su programa de gobierno y con los sucesivos nombramientos de Superior Provincial de los 
franciscanos de Castilla, arzobispo, Cardenal, Inquisidor y todavía más como Regente, hasta su fallecimiento en 1517, Cisneros asume definitivamente una vida e ejercicio del poder.

Esa vida es la que le permitió profundizar en la reforma de las órdenes (García Oro, 1971), y añadir a sus funciones eclesiásticas y políticas sus propios empeños de príncipe renacentista, como la fundación de la Universidad de Alcalá y el apoyo a la edición de numerosas obras de espiritualidad:

Hizo ansimismo nuestro Venerable Cardenal imprimir a su costa, y divulgar, parte en latín y parte trasladados en lengua castellana, algunos libros de piedad, y de devoción; con los quales el siervo de Dios se solía deleitar, y aprovechar para alentar el espíritu en la oración, y para seguir sus santos consejos. Que son las obras que dio a la estampa, a sus expensas, las Epístolas de Santa Catalina de Sena, religiosa dominica. En lengua castellana, las obras siguientes: las Epístolas de Santa Ángela de Fulgino, y Santa Matilde [Libro de la Gracia Especial]; Grados de San Juan Clímaco; Instrucciones de San Vicente Ferrer; Vida de Santo Tomás, arzobispo Cantuariense; Meditaciones de la vida de Cristo N. R. por Landulfo Cartujano; el obispo de Ávila, Tostado [Alonso Fernández de Madrigal] Sobre Eusebio; y las Instrucciones de Santa Clara; y las Constituciones sinodales de su arzobispado, todas en diversos cuerpos, y obras. Y las repartió por todos los conventos de monjas para que se leyesen en el coro y en el refectorio, y atendiesen a su obligación, y para desterrar la ociosidad, y ocupar con santo celo a los fieles con la lección de libros espirituales, de que no había memoria en España, ni estaban en lengua que todos pudiesen gozarlos. (Quintanilla, 1653, p. 141).

A estas y otras muchas publicaciones enumeradas por Sainz Rodríguez (1979, pp. 52-66), habría que añadir por encima de cualquier otra, como él mismo hace, la Biblia Políglota. Estas tareas editoriales las concibe Cisneros como complemento a esa reforma de las órdenes religiosas a las que tantos desvelos dedicó, y miran claramente en la dirección de impulsar una religiosidad cristiana auténtica y consciente:

Reforma signific para el prelado toledano: escuela, estudios bíblicos y patrísticos, empresa editorial y cristianización norteafricana e indiana. Esta meta no conlleva un enfriamiento en la promoción de las reformas en curso. Pero sí apunta a un objetivo práctico: la consolidación de los grupos reformados, ahora parcela clara y en muchos casos autónoma de cada familia religiosa. (García Oro y Pérez López, 2012, p. 49).

Aunque se ha insistido en que la iniciativa editorial del Cardenal no formaba parte de un programa (Freitas, 2007 , p. 23), la intención que ampara la misma no puede ponerse en duda. Sin embargo, hay un rasgo que se desprende de estas acciones y que, como vamos a 
ver, diferencia de manera significativa a Cisneros de Vitoria. El primero, cuya altura de miras religiosa no puede ponerse en duda, mantiene un compromiso pleno con lo que considera necesidades de la Iglesia peninsular más que con la universal. De ahí que no dejara de mirar a Roma desde una perspectiva instrumental: prefirió dar el visto bueno a los nunca entusiastas proyectos de reforma de pontífices tan faltos de ejemplaridad como Julio II (García Oro, 1992, I, pp. 220-225), antes que criticar sus acciones o comprometerse con quienes buscaban la regeneración de la Iglesia cuestionando su autoridad. Sin duda, contribuía a esta actitud contemporizadora del Cardenal su visión política y patriótica más que la religiosa o moral, pero también su propia trayectoria. Mal podía escandalizarse, como Erasmo (Castilla, 2016, p. 85), por las acciones guerreras del pontífice quien se empeñaba en la toma de Orán (Alonso Acero, 2006; Hernández, 1997, p. 13), que debería preludiar la de Jerusalén. Por otra parte, el "papa guerrero", aunque guiado siempre por sus propias ambiciones, mostró más cercanía a la corte española que a la francesa, que llegó incluso a apoyar un proyecto para su deposición mediante el denominado conciliábulo de Pisa (septiembre de 1511), con un número muy reducido de cardenales, entre los que destacaba el español Bernardino López de Carvajal, y abundante presencia de obispos y otros cargos en su mayoría franceses (Cortés, 2006, p. 41). Todo esto beneficiaba los intereses hispanos en Italia, por lo que no sorprende la opinión positiva de Cisneros que "nunca fue cambiada por las circunstancias políticas y militares, que tanto confundieron la línea de este pontificado" (García Oro, 1992, I, p. 280).

La actitud hacia Julio II no era, por otra parte, excepcional. Cisneros siempre cuidó mucho las relaciones con los pontífices. De la colaboración con Alejandro VI, a pesar de su escasa contribución a los ideales de reforma mantenidos por el Cardenal (García Villoslada y Llorca, 1960, pp. 435-437), obtuvo numerosas bulas que ampliaban sus poderes arzobispales y, especialmente, todo lo relativo a la fundación y dotación de la Universidad de Alcalá (García Oro, 1992, I, pp. 124-125). A León X no dejó de reprocharle, como lo haría de manera mucho más indignada y con mayores consecuencias Lutero, que la recaudación de limosnas para la construcción de la basílica de San Pedro fuera gratificada con indulgencias, pero a la vez contribuyó con 2500 ducados al proyecto pontificio (García Oro, 1992, I, p. 286). Como en otros episodios de su biografía, para ganar la voluntad de quienes necesitaba, los rígidos principios del defensor de las buenas costumbres eclesiásticas eran moldeados por la habilidad del administrador.

Conviene tener presente este dato por dos razones: primera, porque el Cardenal -sin dudar de la solidez de su fe- representa una aproximación a todas las facetas de la reforma religiosa más propia del hombre de Estado que fue tanto al frente de sus cargos eclesiásticos como políticos; en segundo lugar, y en conexión con lo anterior, porque no se preocupa de definir ideológicamente los principios religiosos y políticos que guían su actuación, sino que recurre a soluciones prácticas a los problemas que se le van planteando, aunque eso no signifique que carezca de una idea clara de lo que pretende alcanzar. 


\section{Vitoria: un contemplativo contra la falta de ejemplaridad}

De lo dicho se desprende la adscripción de Cisneros a la vida activa, lo que adquiere todavía más verosimilitud cuando se contrasta con la vida de retiro, estudio y -al contrario que el Cardenal- manifestación ideológica que caracteriza a Francisco de Vitoria. Si Cisneros ingresa tardíamente en la observancia franciscana, Vitoria lo va a hacer en el dominico convento de San Pablo de Burgos con veintidós o veintitrés años (Alonso Getino, 1930, p. 20). Poco después de su ingreso, en el Capítulo Provincial celebrado en septiembre de 1506 en ese mismo convento, se proclama el triunfo de la reforma de dicha Orden en España, comenzada hacía más de cuarenta años, no sin presiones para los que se resistieron a la misma (Heredia, 1939; Bataillon, 1986, p. 7; Nieva, 2009).

Vitoria habría de continuar el resto de su vida vinculado a conventos reformados, tanto durante su estancia en París, en el colegio de Santiago (García Villoslada, 1938, p. 8 y 64 y ss.), donde permanece entre finales de 1508 y finales de 1522, como durante su estancia en San Gregorio de Valladolid (Díaz, 2016), entre 1523 y 1526, y en San Esteban de Salamanca, que le acogerá hasta su muerte en 1546.

Este último convento había sido convertido por el P. Juan Hurtado de Mendoza en un ejemplo a seguir entre los de España. Se practicaba en el mismo un régimen de estricta observancia, más riguroso que el exigido para el resto de los conventos reformados. Los dominicos propiciaban entre sus miembros una actitud de plena entrega al estudio (Alonso Getino, 1930, p. 20; Hernández, 1988, p. 33 y ss.), que venía de tiempo atrás (Nieva, 2006), de manera que cuando Vitoria llega a San Esteban en agosto de 1526, encuentra allí el ambiente más favorable para su trabajo universitario, a la vez que reproduce lo que consideraba que eran los modos de vida propios de la Iglesia primitiva.

La vinculación con la reforma de Vitoria no se detiene en su vida conventual, sino que también se expresa como aspiración general en sus escritos. En su caso, no obstante, la dedicación práctica a la reforma de las órdenes y de la Iglesia peninsulares, que caracterizó la acción del Cardenal, se ve sustituida por una preocupación teórica que apenas se detiene en el marco hispano, sino que va a centrarse en los pontífices y en los males generales de la cristiandad, incluyendo el luteranismo, con el que Cisneros no tuvo que luchar.

Vitoria se ocupó de la naturaleza de la potestad papal, estableciendo con claridad su origen y sus relaciones y diferencias respecto del poder civil. Pero quiso también prestar especial atención a la persona que ejerce esa potestad y sus funciones. En relación con éstas, analizó el dominico la licitud y equidad de las actividades papales. Era consciente de que los excesos de los pontífices, obispos, sacerdotes y frailes provocaban, con su falta de ejemplaridad, la desconfianza y el desapego generalizado de los fieles hacia la Iglesia, pero la importancia y autoridad de los primeros los convertía en modelos de conducta en los que todos ponían 
la mirada. Por eso, cuando las dispensas, la asignación y acumulación de beneficios, la no residencia, la venta de indulgencias, la ambición material, las composiciones injustas, etc., parecían usarse en contra del servicio divino, los papas, si no eran partícipes, eran vistos como cómplices. Así, sobre el absentismo en las diócesis, no se duda de su culpabilidad: "La pluralidad de beneficios , en última instancia, la complicidad de Roma aparecen como causas de este abuso" (Tellechea, 1957, p. 88).

¿Cómo poner orden en la Iglesia si su máxima jefatura no ofrecía ejemplo alguno a seguir? Se hacía más necesario que nunca un concilio general que abordara los males de la cristiandad o, al menos, alguna solución a problemas concretos. Vitoria, que tanto en la De potestate ecclesiastica relectio prima (I, 657) como en la De potestate Papae et Concilii (I, 785), se manifiesta abiertamente por la similar probabilidad de las dos opiniones en disputa sobre la superioridad del papa o del concilio en el viejo conflicto que las enfrentaba (Van Liere, 1997), se daba cuenta de que los pontífices del momento tenían miedo a convocarlo por si se volvía en su contra: "Si el Sumo Pontífice temiera que sus hechos se iban a rescindir en el concilio, nunca querría congregar un concilio, con gran perjuicio de los asuntos ecle-siásticos, como queda claro en nuestro tiempo, en el que ya no hay concilios" (De potestate Papae et Concilii, I, pp. 851-853). Se hacía así más evidente la distancia que existía entre la Iglesia de su época y la antigua, en la que se inspiraba su ansia de reforma eclesiástica y donde creía encontrar la solución para buena parte de los males actuales de la república cristiana. En aquella no existían los problemas de potestad entre el papa y el concilio, ni los papas dejaban de lado los acuerdos adoptados por los cardenales y obispos; solo existían la preocupación por el bien común y la búsqueda del mejor servicio a Dios. La dignidad que emanaba de aquellos papas era suficiente para creer en la bondad de sus decretos, mientras que la situación del momento era muy diferente:

En el tiempo de los antiguos concilios los pontífices eran semejantes a los Padres de los concilios, a quienes no había necesidad de enfrentarse con este tipo de decretos por una inmoderada licencia de dispensar; es más, si se consultan cuidadosamente los derechos y las historias, los pontífices no se atrevían a anular los decretos de los con-cilios y tampoco era fácil dispensar, sino que los observaban como oráculos divinos, y no solo no lo hacían con temeridad, sino que quizás ni dispensaban en contra de los decretos de los concilios. Pero poco a poco se ha llegado a tal inmoderación en las dispensas y a un estado tal, que son intolerables nuestros males y hasta sus remedios, y por eso es necesario buscar otros procedimientos para la conservación de las leyes. Denme papas como los Clementes, Linos y Silvestres, y todo lo dejaré a su arbitrio. Mas por no decir nada más grave de los recientes pontífices, ciertamente son inferiores a los antiguos en muchas cualidades. (De Potestate Papae et Concilii, I, 829. He añadido en la parte final la variante del manuscrito de Valencia y de la primera edición de Lyon que figura en el aparato crítico, p. 828) 
Sin duda, Vitoria tenía buenos motivos para añorar aquel tiempo feliz en el que en Roma se predicaba con el ejemplo: "Si presidiese allí san Gregorio, conformarme hía con su determinación; ahora, algún escrúpulo me quedaría" (Carta al P. Miguel de Arcos sobre negocios de Indias, p. 39). Pero, mientras tanto, del temor pontificio a los concilios se des-prendía gran perjuicio para la religión. La falta de deliberaciones había llevado a la Iglesia a una situación calamitosa, convirtiendo el poder papal en una fuente de escándalos entre los que no ocupaban un lugar pequeño la laxitud introducida en el cumplimiento de las normas más elementales. Solo cabía, por tanto, convocar un concilio contra la voluntad del papa, para defender a la Iglesia de sus propios excesos (De potestate Papae et Concilii, I, p. 857). Vitoria era consciente de que muchos gobernantes -junto con otros personajes influyentes- eran los máximos incitadores de muchas de esas acciones inadecuadas en las que incurrían los pontífices

Por esta razón se evitan las maldades y las molestias tanto de los príncipes, que sue-len insistir de forma odiosa a favor de dispensas absurdas y totalmente irracionales, a los que es dificilísi o que el Papa se lo niegue. Y no sólo de los príncipes, sino también de hombres insolentes que esperan conseguir todo de Roma, y tratan de mover al Pontífice a su voluntad, y son pesados y molestísimos. (De potestate Papae et Concilii, I, pp. 847-848).

Pero, incluso con esa opinión más que reticente hacia muchas de las intervenciones de los poderosos en Roma, la gravedad de la situación avala el recurso del dominico para que con su autoridad escucharan los ruegos de la mayoría de los obispos e impidieran cualquier obstáculo papal a lo decidido en dicho concilio: "Hecha esta declaración y decreto del Concilio, si el Sumo Pontífice mandara lo contrario, podrían los obispos o el concilio provincial recurrir también a los príncipes para que cualquiera de ellos se opusiera al Sumo Pontífice, impidiendo sus mandatos" (De potestate Papae et Concilii, I, p. 853).

La intervención de los príncipes en la reforma de la Iglesia no constituía una novedad. Existía al menos un antecedente célebre del que tal vez Vitoria hubiera oído hablar, dada la influenci ejercida por Savonarola en su orden (Heredia, 1972, pp. 520-531). El reformador italiano había pedido a los reyes que acudieran en ayuda de la Iglesia y que corrigieran los excesos papales, a lo que los Reyes Católicos respondieron en 1498 utilizando a fray Tomás de Matienzo, subprior del Convento de la Santa Cruz de Segovia, para que actuase, junto al comendador Sánchez de Londoño, como su embajador ante el rey Enrique VII de Inglaterra con el fin de lograr su apoyo para una acción conjunta de reforma del papado (Pozo Sánchez, 2004).

Fuera bajo el influjo de un antecedente de este tipo o por su propia convicción, la idea de recurrir a los príncipes para salvar a la Iglesia de sus propias dificultades no era algo excepcional para Vitoria. Dos o tres años después de pronunciar la De potestate Papae et Concilii volvería sobre ello al personalizar en un acuerdo entre Francisco I y el emperador Carlos el éxito de cualquier solución a los males eclesiásticos:

Yo por agora no pediría a Dios otra mayor merced, syno que ficiese estos dos 
príncipes verdaderos hermanos en voluntad como lo son en devdo, que sy esto oviese, no avria más herejes en la Yglesia ni aun más moros de los que ellos quesieren, y la Yglesia se rreformaria quisier el Papa o no; y fasta que esto yo vea, ni daré un maravedí por Concilio, ni por todos quantos remedios ni yngenios se ymaginaren. (Carta al condestable de Castilla, D. Pedro Fernández de Velasco, 1981, 1, pp. 291).

En realidad, nadie se oponía a que los papas tomaran las decisiones que les correspondían, pero era evidente que hacía tiempo que en Roma no se actuaba atendiendo al bien evangélico: "A diario vemos que de la curia romana proceden dispensas tan amplias, es más, tan relajadas, que el mundo no las puede aguantar, y no solo son escándalo de menores, sino también de mayores" (De potestate Papae et Concilii, I, p. 799). Como otros muchos, Vitoria no podía ignorar la necesidad de las dispensas, pero lo que estaba concebido para que la norma general no violentara las circunstancias de un caso concreto, no podía justificar una situación en la que la dispensa estaba al alcance de cualquiera. Esta solo se justificaba en casos excepcionales

\footnotetext{
Cuando decimos que no hay que dispensar, no excluimos algún caso que quizá pueda suceder en mil años, que se necesitaría dispensar porque se seguiría algún gran escándalo; entonces con razón se podría dispensar, siempre que estuviera previsto en la ley y no se dejara al arbitrio humano. (De potestate Papae et Concilii, I, p. 811).
}

Sin embargo, la ligereza con la que estas dispensas eran concedidas por los papas, las convertían en algo tan habitual que lo extraño parecía ser el cumplimiento de la ley.

También en lo que respecta a la pluralidad de beneficios y a la no residencia tendían los papas a dispensar más de lo que la equidad hacía aconsejable (Carta al Dr. Luis González, pp. 41-42), lo que a su vez parecía justificar que el resto de la Iglesia actuara en la misma línea

\footnotetext{
Los Pontífices dispuestos a dar beneficios a los parientes sin ulterior selección, pecan mortalmente.

La prueba reside en que tal comportamiento conlleva olvidar a los que son más dig-nos y promover a muchos que no son dignos, pues tales obispos llevan el propósito de dar beneficios a sus parientes sin atender a su dignidad. Además, resulta un gran escándalo en la Iglesia y los que lo dan a los dignos son ocasión también de que otros lo den a los indignos. (De simonía, II, p. 261).
}

Los monasterios, por ejemplo, reclamaban nuevos beneficios cuando los que poseían no eran servidos por sus frailes. sino que se encomendaban a personas mal preparadas ( $A n$ beneficia ecclesiastica uniantur licite monasteriis, p. 50). Incluso la composición, esto es, la búsqueda del perdón por parte del pecador a cambio de una indemnización, se convertía en un negocio cuando caía en manos poco escrupulosas. Así, ante la dificultad de determinar a 
la víctima de una mala acción o a sus parientes, era la autoridad eclesiástica la que negociaba la composición y se beneficiab de la restitución para destinarla a la cruzada contra los infie les, la limosna para los pobres, hospitales, hospicios o a cualquier otra de las labores que tenía encomendada. La solución era razonable siempre que no se cruzara alguien dispuesto a otorgar la absolución a cambio de una cantidad muy inferior a la que correspondía para ser usada no se sabe con qué fines. Este tipo de arreglos eran rechazados por Vitoria, que no veía en ello otra cosa que el deseo de conseguir dinero sin detenerse ante ningún reparo; la penitencia quedaba en estos tratos en un plano muy secundario, deformando con ello la original intención de la pena. En esas condiciones se trataba, dijo en sus lecciones Sobre la justicia (Comentarios a la Secunda Secundae de Santo Tomás, 1934, q. 62, a. 5, n. 12, p. 164), del curso 1535-36, de "la mayor burla del mundo" (Duve, 2008). Así pues, sobre la composición:

[...] yo cierto no predico contra ella, pero a ninguno excuso de restitución por haber compuesto, ni le absuelvo por aquella composición. No porque el papa no lo pueda hacer aquello y más, que non dubito sino que el papa podría mandar absolute, por causa justa, que todos cuantos deben deudas a personas inciertas, den la mitad para la guerra y se queden con la otra mitad; immo el rey lo podría mandar, y haría bien habiendo justa causa. Nec de hoc debet aut potest dubitari. Pero de la forma que se suele hacer, yo no lo entiendo, ne quid asperius dicam; porque ni se hace voluntariamente, sino que el comisario toma lo que le dan, porque no puede sacar más. Por dos reales, le perdona cinco mil, que parece cosa de burla. Así que nec teneo nec dicta refello. Allá se avengan los echacuervos mayores y menores. (Fragmento de una carta sobre la composición, p. 45).

Todavía habría de volver sobre ello en la Carta al P. Miguel de Arcos sobre negocios de Indias (p. 39). Una -otra- señal de la preocupación que embarga a la época, que no cesa de preguntar a sus mejores espíritus sobre el asunto, y síntoma claro también de la opor-tunidad de las palabras de Vitoria ante la persistencia y gravedad de lo debatido. Sin duda, no le faltaban motivos a Vitoria para criticar las actitudes de los hombres de Iglesia de su época. Sin embargo, no fue un rigorista. Pretendía corregir los males existentes, pero estaba lejos de establecer para la vida real una exigencia desmesurada. Con frecuencia estaba más inclinado a quitar barreras que a ponerlas, y apelaba a una determinación respecto a "cómo habemos de vivir, y que no fuese estrecha, sino la más larga que se sufriese" (Carta al Dr. Luis González, pp. 40-41). Vuelve sobre ello en el Fragmento de una carta sobre la composición (p. 45), y en el dictamen An beneficia ecclesiastica uniantur licite monasteriis (p. 50). Incluso prefería pasar por alto una falta, si no resultaba en exceso escandalosa, a castigar al pecador. Así, al prestar servicio a los fieles consideraba preferible un mal menor conocido que la posibilidad de uno mayor, como señalaba respecto al poseedor de varios beneficios, aunque no pudiera residir en todos ellos:

[...] si pone buen cuidado para que su absencia no haga falta, no hay por qué 
compelerle a renunciar el beneficio ni negarle la absolución, especialmente que, mirando cómo van hoy las cosas, es verisimile que, si él lo deja, caerá el beneficio en manos de algún desalmado, que ni tenga cuenta con eso ni con esotro, ni se mate por esos escrúpulos. Y cuanto a la ración y al benefici simple, si de derecho lo puede tener sin dispensación, que no lo sé, no hay por qué le poner escrúpulo. Y si es con dispensación, yo aconsejaría que soltase el uno; pero si no quiere, pues que estudia y es hombre de bien, quédese con ellos y con un poco de escrúpulo. (De pluralitate be-neficioru , p. 44).

Lo importante desde el punto de vista vitoriano no podían ser las dispensas, sino la existencia de leyes serias y convenientes al estado general de la Iglesia. Si estas eran dictadas por la autoridad competente, con una finalidad lícita y vigilando su cumplimiento, la Iglesia se beneficiaría, y los fieles recuperarían la confianza que los abusos les estaban haciendo per-der (De potestate Papae et Concilii, I, p. 811). Solo así se conseguiría una Iglesia que podría recordar lo que fueron sus comienzos: pobre, devota, sacrificada y dispuesta a dar más impor-tancia a la vida en el más allá que a las ambiciones terrenales.

Este modelo idealizado de las comunidades cristianas originales atraía a Vitoria por encima de la triste realidad del presente. Para alcanzarlo debía cambiar la actitud de los fieles, pero lo principal era que se transformara la de los eclesiásticos. La Iglesia, como recordaba en la primera relección Sobre la potestad de la Iglesia (I, p. 465) y en la segunda (I, p. 673), era un cuerpo jerarquizado y, para que la mayoría de sus miembros se comportaran como se esperaba de ellos, debían ser sus dirigentes los que demostraran un mayor cumplimiento de sus normas.

Si la reforma de la Iglesia no alcanzaba a la figura del papa, no sería posible lograr una auténtica cristiandad. Su poco recomendable ejemplo era la mejor excusa para todos aquellos que no estaban dispuestos a aceptar un cristianismo verdadero. Carecía de sentido, además, intentar reformar un cuerpo cuya cabeza rectora se resistía a cambiar. Un concilio donde se discutieran los males de la Iglesia con una voluntad real de reforma, sin disputas en torno a la primacía de la autoridad papal o conciliar, era la única forma de acabar con el presente estado de cosas, insatisfactorio a todos los efectos y que, para empeorar la situación existente en los tiempos de Cisneros, debía soportar el auge del luteranismo.

Vitoria supo diferenciar bien entre la necesidad de reforma de la Iglesia, corrigiendo sus excesos y reivindicando un mayor compromiso con el mensaje evangélico, y su transformación, que atribuyó a las doctrinas de Lutero. No dejará de criticar estas, que consideraba erróneas. Así, se opone a "uno de los dogmas de los luteranos", según el cual "todas las obras de todos los hombres son pecados y dignas de eterno castigo, a no ser que la misericordia divina las haga veniales" (De homicidio, I, p. 221). En realidad, aceptar la idea de que los pecados mortales no pueden ser perdonados y que no se confiere la gracia original por el poder de la penitencia impuesta por la Iglesia sería equivalente a perder toda posibilidad de orientar la vida conforme a lo que se considera la voluntad de Dios (Skinner, 1986, p. 145). 
Por eso, mantiene Vitoria que la persona que se duele de sus pecados y se propone guardar los mandamientos consigue la remisión de sus culpas si no existe ningún otro impedimento (De potestate ecclesiastica relectio prima, I, pp. 492-493).

También denuncia Vitoria la concepción de la Iglesia que defiende Lutero. Para este los cristianos forman una congregación de los fieles donde todos son iguales y no existe ninguna autoridad o potestad (De potestate ecclesiastica relectio prima, I, p. 463). Pero Vitoria rechaza esta idea desorientadora. No todos los fieles son sacerdotes ni, por supuesto, expertos teólogos, que siempre son necesarios. Existe una jerarquía en la Iglesia que tiene su fundamento en las distintas tareas que tienen encomendadas sus miembros: "En verdad, si creemos a Lutero, que los pies podrán decir a la cabeza: no te necesitamos, pues él enseña que los pies, es decir, el pueblo no necesita de la cabeza, es decir, de los sacerdotes, pues son todos sacerdotes" (De potestate ecclesiastica relectio secunda, I, p. 673). La elite de esos sacerdo-tes que -contra Lutero- Vitoria ponía como órgano intelectual de la Iglesia, la constituían los teólogos como él mismo. El dominico tenía de ellos la idea más elevada:

El oficio y cometido del teólogo abarca tanto que ningún argumento, ninguna controversia, ningún asunto parecen quedar fuera de la profesión y objeto de atención del teólogo.

Esta tal vez sea la causa, como del orador decía Cicerón, de que sea tan grande -por no decir mayor- la escasez de buenos y sólidos teólogos, dado que hay tan pocos varones preclaros y excelentes en todo género de disciplinas y en todas las artes. Pues, ciertamente, la teología es la primera de todas las disciplinas y estudios del mundo, aquella a la que los griegos llamaban Tratado de Dios. Por lo cual no debe parecer nada extraño que no haya muchos del todo competentes en materia tan difícil. (De potestate civili, I, p. 83).

\section{Cisneros y Vitoria: diferentes contextos y distintas finalidades}

No deja de ser curioso que Cisneros, que dio su apoyo a iniciativas espiritualistas como la de la Beata de Piedrahita, contra los criterios predominantes en la orden dominica (Heredia, 1972, p. 526), mantenga una concepción muy similar a la de Vitoria, en detrimento de esa experiencia directa de Dios que se manifestaba en mujeres como sor María de Santo Domingo y otras similares. El empeño cisneriano en reformar las órdenes religiosas tenía como finalida principal convertirlas en una vanguardia consciente y verdaderamente capacitada para llevar al pueblo cristiano los evangelios; sin embargo, con este modelo el laico quedaba limitado al "papel de receptor y creyente pasivo de la enseñanza de los entendidos" (Pérez García, 2006 p. 78), lo que venía a restringir la autonomía de los fieles. Esta dependencia acentuaba el contraste con la teología que Erasmo y en mayor medida Lutero estaban desarrollando, 
más centrada en la regeneración de los laicos por vía directa, a la vez que parece otorgar más coherencia a las propuestas de Vitoria que a las acciones mudables del propio Cardenal.

Otra importante coincidencia entre Cisneros y Vitoria que puede relacionarse con sus simpatías reformistas, pero que no cabe negar que estaba muy asentada en su tiempo (Van Liere, 2000, p. 81), es su desconfianza hacia la labor de los juristas. Con su conversión franciscana, el Cardenal renegó de la ciencia jurídica que había estudiado en Salamanca y que tan útil le había sido para mejorar su posición social y la de sus colaboradores y parientes (García Oro, 1992, I, pp. 109-112 y pp. 233-236 (para sus colaboradores), y pp. 230-232 y 458 y ss. (para sus familiares)). No quiso incluir esas enseñanzas en la Universidad de Alcalá, considerando que eran suficientes las que proporcionaban universidades como Salamanca y Valladolid. Su objetivo era formar a la élite clerical del reino, no preparar para una carrera a la que atribuía una finalidad más lucrativa que científica o benefi iosa para la sociedad (Pérez, 2014 , p. 230). Esta suspicacia ante el derecho, pero, sobre todo, frente a sus practicantes, encuentra de nuevo en Vitoria un equivalente, también más dirigido a los abogados que a la ciencia en la que eran expertos. No le faltaban al dominico ocasiones para reconocer la necesidad o conveniencia de recurrir a su saber:

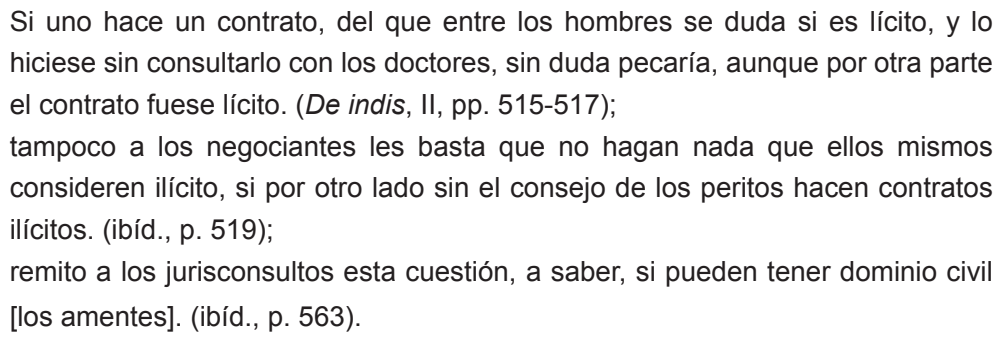

Pero sus menciones expresan más bien críticas por lo que considera una actividad legitimadora de tesis nuevas y discutibles, las novedades tan asociadas a desórdenes en la época:

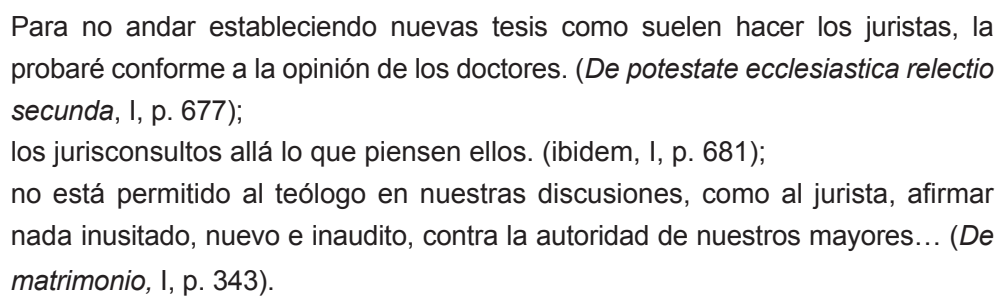

Esta tendencia chocaba claramente con el compromiso moral del teólogo con el que se identificaba el dominico, de manera que no sorprende que vea en "el error de muchos jurisconsultos" al afirmar que el papa es señor del orbe con autoridad y jurisdicción temporal 
"una verdadera invención para adulación y lisonja de los pontífices" (De potestate ecclesias-tica relectio prima, I, pp. 541-543). De la misma forma, frente a los que dicen que "el papa instituye toda potestad temporal como delegada y subordinada a sí mismo, y que él mismo constituyó a Constantino emperador", responde que es algo:

Ficticio y sin ninguna probabilidad, y ni se apoya en la razón o en el testimonio de las Escrituras o al menos de alguno de los Padres o verdaderos teólogos. Pero los glosadores del derecho, tan pobres en bienes como en doctrina, concedieron este dominio al papa. (De potestate ecclesiastica relectio prima, I, pp. 545-547).

No sería justo dejar de recordar que esta atribución a los juristas de estar más preocupados por el propio interés y, sobre todo, por obtener beneficio material de su saber que, por la verdad, se produce en un contexto en el que existe una clara competencia entre ellos y los teólogos. Es una competencia que tiene mucho que ver con la grandeza intelectual que los juristas atribuyen a su disciplina, que los lleva a considerar sin ningún complejo que la jurisprudencia es la verdadera filosofía e incluso la vera theologia (Kelley, 1976, p. 269). También tiene que ver con la estima con la que ellos mismos se proyectan frente a otros hombres de saber, como los filósofos, los teólogos y, muy pronto, los científicos o filósofos naturales (Kelley, 1988). A su vez esta elevada imagen coincide con un momento en el que los más altos cargos de la burocracia eclesiástica y regia de la monarquía hispana se asignan tanto a los juristas como a los teólogos. Quizá esta situación no pasó desapercibida a la hora de juzgar a sus rivales pero, en cualquier caso, debería hacer meditar a los que han querido convertir a Vitoria, por encima de cualquier otra consideración y sin excesivos matices, en un teólogo-jurista y en fundador del derecho internacional.

En definitiva, dos frailes observantes, el franciscano Cisneros, desde la vida activa, y el dominico Vitoria, desde la contemplativa, representan dos maneras de abordar la reforma de la Iglesia y sus males. El primero inmerso en posiciones de poder religioso y político, aparece siempre preocupado por la corrección de las órdenes religiosas de su país, lo que para él -en connivencia con los Reyes Católicos- equivale a convertir a la observancia a todos sus miembros; lo que pretende con esta medida, con la formación teológica impartida en la Universidad de Alcalá y con las lecturas editadas por su iniciativa, es alcanzar a construir una élite capaz de hacer llegar con su ejemplo de vida y su saber la palabra de Dios al pueblo. Vitoria no forma parte de la cosecha alcalaína de Cisneros, pero si se inscribe por sus propios méritos en esa élite. El dominico considera prioritario conseguir un cambio en la cabeza de la Iglesia; cree que con obispos y, sobre todo, con un papa ejemplar, se podrá restaurar lo que en sus inicios fue la república cristiana, única esperanza para poder superar la división del cristianismo a la que asiste. Tal vez, por encima de su desigual énfasis, la diferencia fundamental entre uno y otro se encuentre en lo que Vitoria vivió como una situación de hecho y Cisneros no llegó a conocer: el éxito del luteranismo, que obligaba a una acción reformadora sin límites doctrinales, organizativos ni geográficos 
Esta distinción, por otra parte, permite llamar la atención sobre un aspecto de la reforma hispana que quizá hasta ahora no ha sido muy tenido en cuenta. Vicente Beltrán de Heredia (1938, 1939 y 1972), Eugenio Asensio (2000 [1952]), y José Antonio Maravall (1967 [1956]), que serían seguidos de una u otra forma por la casi totalidad de los estudiosos de estas materias, defendieron muy tempranamente, matizando las conclusiones a las que llegaba Marcel Bataillon en su excelente Erasmo y España (1986), la existencia de unas corrientes de espiritualidad peninsulares anteriores al erasmismo aunque coincidentes con este en sus anhelos generales de reforma del cristianismo y en algunas de las expresiones y autoridades citadas en sus escritos. No todas estas corrientes compartían los fines concretos y muchos de los medios de los que se servía Erasmo para apoyar aquella reforma a la vez que mostraban con frecuencia afinidades con otros autores y movimientos ajenos al holandés. De manera que la religiosidad hispana de finales del siglo XV e inicios del XVI se caracterizaba por una diversidad e influencias que estaban muy lejos de poderse definir exclusivamente en relación a Erasmo. Incluso los mismos erasmistas españoles, que no dejaban de ser un grupo elitista y minoritario (Pérez, 1986, p. 338), distaban de constituir un movimiento unitario: no seguían al holandés de igual manera (Pastore, 2015, p. 258) y por las mismas razones. Los había atraídos por su "espiritualismo anticeremonial y antiescolástico", como otros se sentían identificados con "su evangelismo", mientras que abundaban también "los que se quedaron solo en sus exigencias filol gicas del "buen latín”" (García Cárcel, 1998ª , p. 4) y los que paladeaban la frescura de sus escritos y la accesibilidad de sus textos (Serés, 2015).

Por otra parte, muchos erasmistas se mostraban más conciliadores que su inspirador a la hora de aceptar prácticas sobre las que aquel vertía su ironía (Asensio, 2005), y traducciones como la del Enchiridion contribuyeron a suavizar sus sarcasmos (Abellán, 1982, p. 101), hasta el punto de hacer pensar si era una actitud más propia de censores que de admiradores de Erasmo (García Cárcel, 1998a , p. 11 y 1998b, p. 45). Añadiendo a todo esto la apuesta reformista de Cisneros y Vitoria, deberíamos concluir que también dentro de esas corrientes peninsulares desarrolladas en ocasiones con influencias diferentes de las del holandés, en paralelo con sus propuestas e incluso en oposición a algunas de ellas, había diferencias al menos entre los que postulaban cambios en el ámbito hispano y en el general de la Iglesia, como los había igualmente en los que se esforzaban por materializarlas desde sus cargos políticos o desde posiciones teóricas.

\section{Bibliográfica}

ALONSO, B. (2006). Cisneros y la conquista española del norte de África: cruzada, política y arte de la guerra. Madrid: Ministerio de Defensa.

ALONSO, L. G. (1930). El Maestro Fray Francisco de Vitoria. Su vida, su doctrina e influencia Madrid: Imprenta Católica. 
ANDRÉS, M. (1988). "La espiritualidad franciscana en tiempo de las observancias (1380- 1517)" Studia Historica. Historia moderna, (6), 465-479.

ANDRÉS, M. (2000; 1976). La teología española en el siglo XVI. Madrid: BAC, 2 vols.

ASENSIO, E. (1952). El erasmismo y las corrientes espirituales afine. Salamanca: Seminario de Estudios Medievales y Renacentistas.

AZCONA, T. de. (2015). "La reforma religiosa y la confesionalidad católica en el reinado de Isabel I de Castilla, la Católica”. Carthaginensia, (31), 111-136.

BARON, H. (1993). En busca del humanismo cívico florentino. Ensayos sobre el cambio del pensamiento medieval al moderno. México: Fondo de Cultura Económica.

BARRIO, M. (2014). "Los Reyes Católicos, Cisneros y la reforma del clero secular y regular". En J. A. Escudero (dir.), La Iglesia en la historia de España (pp. 415-432). Madrid: Fundación Rafael del Pino Marcial Pons.

BATAILLON, M. (1986). Erasmo y España. Estudios sobre la historia espiritual del siglo XVI. Madrid: F.C.E. BELTRÁN DE HEREDIA, V. (1931). "Colección de dictámenes inéditos del maestro fray Francisco de Vitoria”. La Ciencia Tomista, (XLIII), 27-50 y 169-180.

BELTRÁN DE HEREDIA, V. (1938). "Erasmo y España. A propósito de un libro". La Ciencia Tomista, (57), 544-582.

BELTRÁN DE HEREDIA, V. (1972; 1939-1941; 1941). "Las corrientes de espiritualidad entre los dominicos de Castilla durante la primera mitad del siglo XVI”. Miscelánea Beltrán de Heredia, (III), 519-671. Salamanca: Editorial OPE.

BELTRÁN DE HEREDIA, V. (1939). Historia de la reforma de la Provincia de España (1450-1550). Roma. Institutum Historicum FF. Praedicatorum.

CARO BAROJA, J. (1970). El señor Inquisidor y otras vidas por ofic o. Madrid: Alianza.

CASTILLA, F. (2016). Propuestas utópicas e insuficiencias políticas: Erasmo y el cuerpo místico de Cristo. Revista Española de Filosofía Medieval, (23), 67-86.

CASTILLA, F. (2002). El análisis social de Julio Caro Baroja: empirismo y subjetividad. Madrid: CSIC.

CASTILLA, F. (2013). El pensamiento de Juan Ginés de Sepúlveda: vida activa, humanismo y guerra en el Renacimiento. Madrid: CEPC.

CORTÉS, A. L. (2006). "La crisis de la cristiandad occidental en los albores de la modernidad”. En: A. L. Cortés (coord.). Historia del cristianismo III. El mundo moderno (pp. 17-50). Madrid: Editorial Trotta Universidad de Granada.

DÍAZ, J. (2016). Alonso de Burgos y la fundación y primeros estatutos del colegio de San Gregorio de Valladolid. Cuadernos de Historia del Derecho, (23), 41-100.

DUVE, T. (2008). ¿ “La mayor burla del mundo"? Francisco de Vitoria y el dominium del Papa sobre los bienes de los pobres. En J. Cruz (Ed.), Ley y dominio en Francisco de Vitoria (pp. 93-106). Pamplona. Eunsa.

FREITAS, J. A. de. (2007). Lectura espiritual en la península Ibérica (siglos XVI-XVII). Salamanca: SEMYR - Centro Interuniversitário de História da Espiritualidade (Universidade do Porto).

GARCÍA, R. (1998a). "Bataillon y las corrientes espirituales periféricas". En J. Pérez (dir.), España y América en una perspectiva humanista: Homenaje a Marcel Bataillon. Madrid. Casa de Velázquez. 
GARCÍA, R. (1998b). "De la reforma protestante a la reforma católica. Reflexiones sobre una transición". Manuscrits, (16), 19-63.

GARCÍA, J. (1971). Cisneros y la reforma del clero español en tiempo de los Reyes Católicos. Madrid: CSIC. GARCÍA, J. (1992). El cardenal Cisneros. Vida y empresas. Madrid: BAC, 2 vols.

GARCÍA, J. (1969). La reforma de los religiosos españoles en tiempo de los Reyes Católicos. Valladolid: Instituto Isabel la Católica de historia eclesiástica.

GARCIA, J. y PÉREZ, L. (2012). "La reforma religiosa durante la gobernación del cardenal Cisneros (15161518): hacia la consolidación de un largo proceso". Annuarium Sancti lacobi, (1), 47-174.

GARCíA, R., S.I. y LLORCA, B., S.I. (1960). Historia de la Iglesia Católica III. Edad Nueva. La Iglesia en la época del Renacimiento y de la Reforma católica. Madrid: BAC.

GARCíA, R. (1938). La Universidad de París durante los estudios de Francisco de Vitoria O.P. (15071522). Roma: Universitatis Gregorianae.

HERNÁNDEZ, M. I. (1997). El taller historiográfico: cartas de relación de la conquista de Orán (1509) y textos afine . London: Department of Hispanic Studies Queen Mary and Westfield College.

HERNÁNDEZ, R. (1985; 1988). "F. de Vitoria en la crisis de su tiempo". En I diritti dell'uomo e la pace nel pensiero di F. de Vitoria e B. de las Casas (pp. 31-62). Congresso Internazionale tenuto alla Pontificia Univ. S. Tommaso (Angelicum). Roma, 4-6.3. Milano: Massimo.

KELLEY, D. R. (1988). "Jurisconsultus perfectus. The Lawyer as Renaissance Man". Journal of the Warburg and Courtauld Institutes, (51), 84-102.

KELLEY, D. R. (1976). "Vera Philosophia: The Philosophical Significance of Renaissance Jurisprudence”. Journal of the History of Philosophy, 14, (3), 267-279.

MARAVALL, J. A. (1967). "La idea del cuerpo místico en España antes de Erasmo". En Estudios de Historia del Pensamiento Español. Edad Media. Serie Primera. Madrid. Ediciones Cultura Hispánica.

MARTÍNEZ, J. (2011). El cardenal Cisneros, un gran patrón cortesano. En M. Á. de Bunes; B. Alonso (Coords.), Orán. Historia de la corte chica (pp. 83-117). Madrid. Polifemo.

MESEGUER, J. (1959). "Franciscanismo de Isabel la Católica". Archivo Ibero-Americano, (19), 153-195.

NIETO, J. M. (1990). "Franciscanos y franciscanismo en la política y en la corte de la Castilla Trastámara (1369-1475)". Anuario de Estudios Medievales, (20), 109-131.

NIEVA, G. (2006). "La creación de la observancia regular en el convento de San Esteban de Salamanca durante el reinado de los Reyes Católicos”. Cuadernos de historia de España, (LXXX), 91-126.

NIEVA, G. (2009). Reformatio in membris: conventualidad y resistencia a la reforma entre los dominicos de Castilla en el siglo XV. En la España Medieval, (32), 297-341.

PASTORE, S. (2015). "España en Europa: conversos, alumbrados e identidad hispánica en la obra de Marcel Bataillon". En E. Serrano (coord.), Erasmo y España, 75 años de la obra de Marcel Bataillon (1937-2012), (pp. 249-270). Institución Fernando el Católico. Excma. Diputación de Zaragoza.

PÉREZ, R. M. (2006). "Pensamiento teológico y movimientos espirituales en el siglo XVl”. En A. L. Cortés. Historia del cristianismo III. El mundo moderno, (pp. 51-90). Madrid: Editorial Trotta - Universidad de Granada.

PÉREZ, J. (1986). "El erasmismo y las corrientes espirituales afines". En M. Revuelta y C. Morón (eds.), El erasmismo en España, (pp. 323-338). Santander. Sociedad Menéndez Pelayo. 
PÉREZ, J. (2014). Cisneros, el cardenal de España. Madrid: Taurus.

POZO, B. (2004). "Savonarola y la monarquía española de los ss. XV y XVI". En J. Benavent; I. Rodríguez y D. WEISNSTEIN (eds.). La figura de Jerónimo Savonarola O. . y su influencia en España y Europ (pp. 239-252). Florencia: Sismel.

QUINTANILLA Y MENDOZA, P. de. (1653). Archetypo de virtudes, espejo de prelados. Palermo: Nicolás Bua. RUCQUOI, A. (1996). "Los franciscanos en el Reino de Castilla". En J. I. Iglesia; J. I. de la Duarte; F. J.

García; J. Á. García de Cortázar (Coords.). VI Semana de Estudios Medievales, (pp. 65-86). Nájera, 31 de julio al 4 de agosto de 1995.

RUMMEL, E. (1999). Jimenez de Cisneros: On the Threshold of Spain's Golden Age. Tempe, Arizona:

Arizona Center for Medieval and Renaissance Studies.

SAINZ, P. (1979). La siembra mística del cardenal Cisneros y las reformas en la Iglesia. Madrid: Real Academia Española.

SERÉS, G. (2015). "La "estrategia literaria" de Erasmo y su proyección en la literatura áurea”. En E.

Serrano (coord.), Erasmo y España, 75 años de la obra de Marcel Bataillon (1937-2012), (p. 123-157). Institución Fernando el Católico. Excma. Diputación de Zaragoza.

SKINNER, Q. (1986; 1978). Los fundamentos del pensamiento político moderno. II. La Reforma. México: FCE. TELLECHEA, J. I. (1957). "Francisco de Vitoria y la reforma católica. La figura ideal del obispo" Revista española de derecho canónico, 12 (34), 65-110.

TORRE, A. de la. (1940). "Cisneros, confesor de la Reina”. Hispania, (1), 1940, 43-51.

VALERO, J. M. (2015). "Antecedentes y encrucijadas de la vida activa y contemplativa en la Castilla del Cuatrocientos". eHumanista, (29), 32-71.

VAN LIERE, K. E. (2000). "Humanism and Scholasticism in Sixteenth-Century Academe: Five Student Orations from the University of Salamanca". Renaissance Quarterly, (53, 1), 57-107.

VAN LIERE, K. E. (1997). "Vitoria, Cajetan, and the Conciliarists". Journal of the History of Ideas, $(58,4)$, 597-616.

VÁZQUEZ, F. (2016). “Un problema de historiografía y cronología: la fecha de nacimiento del cardenal Jiménez de Cisneros". Hispania Sacra, (LXVIII, 137), 281-298.

VITORIA, F. de. De los que se retraen por delitos a las Iglesias. En V. Beltrán de Heredia. "Colección de dictámenes inéditos...".

VITORIA, F. de. (1981). "Carta al condestable de Castilla, D. Pedro Fernández de Velasco". En L. de Pereña y otros (Ed.), Relectio de lure Belli o Paz Dinámica. PEREÑA. Madrid: CSIC.

VITORIA, F. de. De homicidio. En F. de Vitoria, Relecciones jurídicas y teológicas, I.

VITORIA, F. de. De indiis. En F. de Vitoria, Relecciones jurídicas y teológicas, II.

VITORIA, F. de. De matrimonio. En F. de Vitoria, Relecciones jurídicas y teológicas, I.

VITORIA, F. de. De potestate civili. En F. de Vitoria, Relecciones jurídicas y teológicas, I.

VITORIA, F. de. De potestate ecclesiastica relectio prima. En F. de Vitoria, Relecciones jurídicas y teológicas, I. VITORIA, F. de. De potestate ecclesiastica relectio secunda. En F. de Vitoria, Relecciones jurídicas y teológicas.

VITORIA, F. de. De potestate Papae et Concilii. En F. de Vitoria, Relecciones jurídicas y teológicas, I. VITORIA, F. de. De simonia. En F. de Vitoria, Relecciones jurídicas y teológicas, II. 
VITORIA, F. de. (2017). Relecciones jurídicas y teológicas. Edición crítica dirigida por A. Osuna Fernández-Largo. Salamanca: Editorial San Esteban, 2 tomos.

VITORIA, F. de. Carta al Dr. Luis González. En V. Beltrán de Heredia. "Colección de dictámenes inéditos...". VITORIA, F. de. An beneficia ecclesiastica uniantur licite monasterii . En V. Beltran. "Colección de dictámenes inéditos...".

VITORIA, F. de. (1988). "Miguel de Arcos sobre negocios de Indias". En: Escuela de Salamanca, Carta magna de los indios. Ed. L. Pereña y C. Baciero. Madrid: CSIC.

VITORIA, F. de. (1934). De iustitia. En: F. de Vitoria. Comentarios a la Secunda Secundae de Santo Tomás. V Beltrán de Heredia (Ed.). Salamanca: Biblioteca de Teólogos Españoles, t. 3.

VITORIA, F. de. De pluralitate beneficioru . En V. Beltrán de Heredia. "Colección de dictámenes inéditos...". VITORIA, F. de. Fragmento de una carta sobre la composición. En V. Beltrán de Heredia. "Colección de dictámenes inéditos...". 